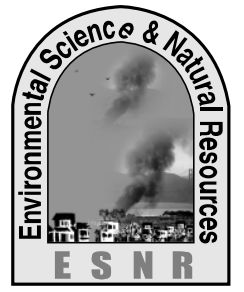

J. Environ. Sci. \& Natural Resources, 5(2): 97 - 107, 2012

ISSN 1999-7361

\title{
Trend and Variability Analysis and Forecasting of Wind-Speed in Bangladesh
}

\author{
J. A. Syeda
}

Department of Statistics, Hajee Mohammad Danesh Science and Technology University, Dinajpur, Bangladesh

\begin{abstract}
An attempt was made to examine the trend and variability pattern for decadal, annual and seasonal (crop seasons) average prevailing wind-speed (APWS) for six divisional stations in Bangladesh namely Dhaka, Rajshahi, Khulna, Barisal, Sylhet and Chittagong. The monthly APWS (2009-2012) were forecasted using univariate Box-Jenkin's modeling techniques on the basis of minimum root mean square forecasting error. The growth rates for annual and seasonal APWS were found to be negative with nonstationary but normal residual for all regions except Barisal and the Prekharif season for Khulna. The rates for Barisal were observed positive with normal and nonstationary residual. The significant positive growth rate for coefficient of variations (CV) of the annual APWS was experienced for Khulna $\left(0.155^{*}\right)$ and the less positive rate for Rajshahi $(0.011)$ with nonstationary residual while for others it was established as negative. The findings support that the climate of this country is changing in terms of the APWS.
\end{abstract}

Key word: Analysis, Trend, Wind-Speed

\section{Introduction}

The agro-based country Bangladesh is affected by climatic hazards. Wind is a vital environmental element for life. It controls the exchange of atmospheric constituents between the crop and the surrounding air. It helps in transferring $\mathrm{O}_{2}, \mathrm{CO}_{2}$ and water vapor (Lenka, 1998) and affects crops in various ways. It influences evaporation, transpiration and evapotranspiration too. If wind-speed increases, evaporation and evapotranspiration are also increases. As a result, leaf vibration, leaf temperature, respiration, etc. increases and photosynthesis become reduced with stomata closing. Higher wind velocity creates harmful and destructive effects through breaking and / or uprooting plants, lodging several crops and thereby grain yield is also affected. Heavy wind during blooming reduces pollination, causes flower-shed, increases sterility and finally reduces fruit sets. On the other hand, lower wind velocity makes beneficial effects. Gentle wind increases turbulence in the crop canopy and improve grain yield. Again hot wind can reduce plant growth but hot windy day is more tolerable than a hot humid day. But wind-speed receives relatively little attention in the literature compared to other meteorological variables. The prediction of atmospheric parameters is essential for various applications like climate monitoring, drought detection, severe weather prediction, agriculture and production, planning in energy and industry, communications, pollution dispersal etc. Nonetheless, an accurate prediction of weather parameters is a difficult task due to the dynamic nature of atmosphere. Hence, the Present work was designed to present trend and variability analysis and forecasting of wind-speed in Bangladesh.

\section{Sources of Data and Methodology}

\subsection{Sources of Data}

The data were taken from Bangladesh Meteorological Department, Dhaka. The monthly average prevailing wind-speed (APWS) were taken for six stations: Dhaka, Rajshahi, Khulna, Barisal, Sylhet and Chittagong for 1953-2008, 1964-2008, 1948-2008, 1949-2008, 1956-2008 and 1949-2008, respectively. The missing data were filled in by the median of the corresponding years. The seasonal data for three crop seasons: Prekharif, Kharif and Rabi were made by averaging the monthly data taking from March May, June - October and November - February, respectively. A divisional map of Bangladesh is shown in Fig. 1.

\subsection{Methodologies}

In this section, The within and between-year variability for the annual and seasonal APWS were calculated. The linear trend (LT) for the annual and seasonal APWS were fitted with the least square method taking the following form of equation-

$\mathrm{Y}=\mathrm{a}+\mathrm{bX}$

Where, $\mathrm{Y}=\mathrm{APWS}, \mathrm{X}=$ time, $\mathrm{a}$ and $\mathrm{b}=$ parameters 


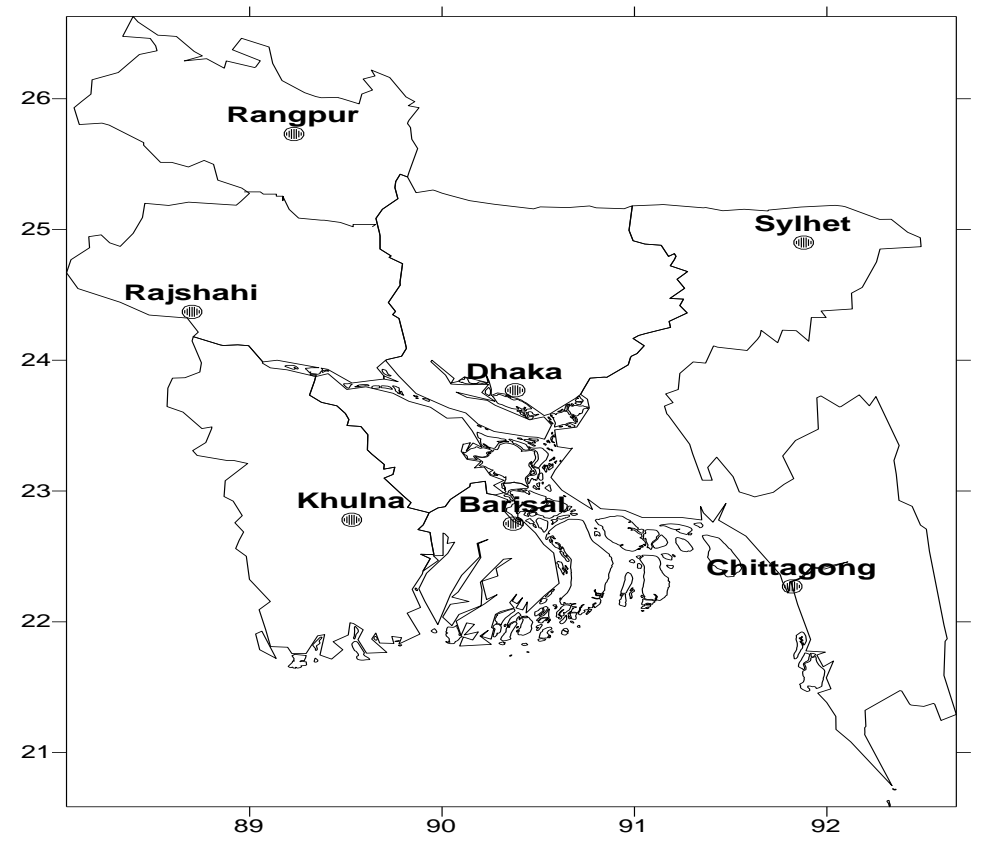

Stationarity of residuals for APWS trend was tested using the ACF and the PACF display and the normality was checked by normal probability plot. The value of classical ' $t$ ' test was used for the identification of significant APWS trend when residuals follow normality and stationarity pattern.

Univariate Box-Jenkin's ARIMA model was fitted to forecast the monthly APWS data for January 2009December 2012. After confirming that the series was stationary, an effort was made for an ARIMA model to express each observation as the linear function of the previous value of the series (autoregressive parameter) and of the past error effect (moving average parameter). The available data were divided into training, validation and test sets. The training set was used to build the model, the validation set was used for parameter optimization and the test set was used to evaluate the model. The adequacy of the above model was checked by comparing the observed data with the forecasted results. In this study, the data for the last ten years were used to compare with the fitted model forecasts for the years and the models are selected for the minimum root mean square forecasting error for the data set of those ten years. The diagnostic techniques namely histogram of residuals, normal probability plot of residuals, ACF and PACF display of residuals, TS plots for residual versus fitted values and TS plots for residual versus order of the data are used for checking residuals of the ARIMA models. Box-Cox transformation was used for variance stabilization and the transformation of the data to get stationary series from nonstationary series (Pankraiz, 1991). The software package "Minitab 13" was used to fit the univariate ARIMA models.

\subsubsection{Box Jenkins Modeling Strategy and ARIMA Model}

Box Jenkins (1976) formalized the ARIMA modelling framework in three steps: (I) Identification (II) Estimation and (III) Verification. In the identification stage, it was tried to identify that how many terms to be included was based on the autocorrelation function (ACF) and partial autocorrelation function (PACF) of the differenced and/or transformed time series (Box Jenkins, 1976). In the estimation stage, the coefficients of the model were estimated by the maximum likelihood method. The verification of the model was done through diagnostic checks of the residuals (histogram or normal probability plot of residuals, standardized residuals and ACF and PACF of the residuals). The performance of the ARIMA models was often tested through the comparison of prediction with observation not used in the fitted model. An appropriate ARIMA model provides minimum root mean squared error forecasts among all the linear univariate models with the fixed coefficients. It could produce point forecasts for each time period and interval forecasts constructing a confidence interval around each point forecast. To have the $95 \%$ interval for each forecast the formulae $f \pm 2 s$ was used, where $f$ denoted a forecast and $s$ was its standard error. The 
forecasts for a stationary model converge to the mean of the series and the speed of converging movement depends on the nature of the model. For nonstationary model, the forecasts did not converge to the mean. A detailed description of the nonseasonal and seasonal ARIMA models and the standardized notation are explored in the following.

\section{Standardized ARIMA Notations}

The ARIMA models have a general form of $\mathrm{p}, \mathrm{d}, \mathrm{q}$ where $\mathrm{p}$ is the order of the standard autoregressive term AR, $\mathrm{q}$ is the order of the standard moving average term MA, and $d$ is the order of differencing AR describes how a variable $y_{t}$ such as wind-speed depends on some previous values $\mathrm{y}_{\mathrm{t}-1}, \mathrm{y}_{\mathrm{t}-2}$ etc. while MA describes how this variable $y_{t}$ depends on a weighted moving average of the available data $\mathrm{y}_{\mathrm{t}-1}$ to $\mathrm{y}_{\mathrm{t}-\mathrm{n}}$. For example, for a one step ahead forecast (suppose: for $\mathrm{t}$ being September) with an AR-1, all weight is given to the wind-speed in the previous month (September), while with an AR-2 the weight is given to the wind-speed of the two immediately previous months (September and August). By contrast, with a MA-1, MA-2, a certain weight is given to the wind-speed of the immediately previous month (September), a smaller weight is given to the wind-speed observed two months ago (August) and so forth, i.e., the weights decline exponentially.

The combined multiplicative seasonal ARIMA ( $p, d$, q) $\times 12(\mathrm{P}, \mathrm{D}, \mathrm{Q})$ model gives the following:

$$
\phi_{p}(B) \Phi_{p}\left(B^{s}\right) \nabla_{s}^{D} \nabla^{d} z_{t}=C+\theta_{q}(B) \Theta_{Q}\left(B^{s}\right) \varepsilon_{t}
$$

The standard expression of ARIMA model where B denotes the backward shift operator where

$$
-\phi_{p}(B)=1-\phi_{1} B-\phi_{2} B^{2}-\ldots-\phi_{p} B^{p}
$$

The standard autoregressive operator of order $\mathrm{p}$

$$
\text { - } \Phi_{p}\left(B^{s}\right)=1-\Phi_{1} B-\Phi_{2} B^{2}-\ldots-\Phi_{p} B^{p s}
$$

The seasonal autoregressive operator of order $\mathrm{p}$

$-\nabla_{s}^{D}$ is the seasonal differencing operator of order D

$-\nabla^{d}$ is the differencing operator of order $\mathrm{d}$

$-\mathrm{y}_{\mathrm{t}}$ is the value of the variable of interest at time $\mathrm{t}$

- $C=\mu \phi_{p}(B) \Phi_{p}\left(B^{s}\right)$ is a constant term, where $\mu$

is the true mean of the stationary time series being modeled. It was estimated from sample data using the approximate likelihood estimator approach.

$$
\text { - } \theta_{q}(B)=1-\theta_{1} B-\theta_{2} B^{2}-\ldots-\theta_{q} B^{q}
$$

The standard moving average operator of order $\mathrm{q}$

$$
\text { - } \Theta_{Q}\left(B^{s}\right)=1-\Theta_{1} B^{1}-\Theta_{2} B^{2}-\ldots-\Theta_{Q} B^{Q S}
$$

The seasonal moving average operator of order Q $-\phi_{1}, \phi_{2, \ldots . .,} \phi_{p} ; \Phi_{1}, \Phi_{2}, \ldots, \Phi_{p} ; \theta_{1}, \theta_{2}, \ldots, \theta_{q}$; $\Theta_{1} \Theta_{2}, \ldots, \Theta_{Q}$ are unknown coefficients that are estimated from sample data using the approximate likelihood estimator approach.

$-\varepsilon_{\mathrm{t}}$ is the error term at time at time $\mathrm{t}$

$-\mathrm{S}$ is the annual period, i,e. 12 months

Thus, the multiplicative seasonal modeling approach with the general form of ARIMA $(p, d, q) \times S(P, D$, $\mathrm{Q})$ has been used in this paper. In this form, $p$ is the order of the seasonal autoregressive term (ARS), Q is the order of the seasonal moving average term, D is the order of the seasonal differencing and $\mathrm{s}$ is the annual cycle (e.g, s = 12 using the monthly data). ARS describes how the variable $\mathrm{y}$ depends on $\mathrm{y}_{\mathrm{t}-12}$ (ARS-1), $\mathrm{y}_{\mathrm{t}-24}$ (ARS-2), etc., while MAS describes how $y$ depends on a weighted moving average of the available data $\mathrm{y}_{\mathrm{t}-12}$ to $\mathrm{y}_{\mathrm{t}-12 \mathrm{n}}$. For example, for a one step ahead forecast (suppose: for $\mathrm{t}$ being September and with an ARS-1, all weight is given to the windspeed in the previous September while with an ARS2 , the weight is given to the September wind-speed 1 and 2 years ago. By contrast, with a MAS-1, MAS-2, the model gives a certain weight to September windspeed 1 year ago, to the September wind - speed 2 years ago, and so on. These weights decline exponentially.

\section{Results and Discussions}

The findings obtained from the analyses of wind-speed are presented below under different captions.

\subsection{Decadal Variability}

The decadal averages for annual and seasonal APWS for six divisions of Bangladesh are presented in the Table 1. The decadal annual APWS of Dhaka decreased from 4.7 during 1953-60 to 2.9 in 1991-00 and increased from 2.9 during 1991-00 to 3.7 in 2001-08. Similar pattern was observed for Kharif, Prekharif and Rabi seasons.

The decadal annual APWS for Khulna decreased from 3.1 during $1948-50$ to 3.0 in 1951-60 and increased from 3.0 during 1951-60 to 4.4 in 1961-70 and again decreased from 4.4 during 1961-70 to 3.2 in 1971-80 and increased from 3.2 during $1971-80$ to 4.0 in 1981-90 and lastly decreased from 4.0 during 198190 to 2.6 in 2001-08. Similar pattern is observed during Prekharif and Rabi season. Kharif APWS increased from 2.9 during 1948-50 to 4.5 in 1961-70 and decreased from 4.5 during $1961-70$ to 3.4 in 197180 and again increased from 3.4 during 1971-80 to 
4.3 in 1981-90 and lastly decreased from 4.3 during $1981-90$ to 2.8 in $2001-08$.

The decadal annual APWS for Rajshahi increased from 2.8 during $1964-70$ to 3.9 in 1981-90 and decreased from 3.9 during $1981-90$ to 2.7 in 2001-08. The similar pattern was observed for Kharif, Prekharif and Rabi season.

The decadal annual APWS for Barisal decreased from 3.6 during $1949-50$ to 2.7 in 1951-60 and increased from 2.7 in 1951-60 to 4.7 in 1971-80 and decreased from 4.7 during 1971-80 to 3.8 in 1981-90 and again increased from 3.8 during 1981-90 to 4.9 in 1991-00 and finally decreased from 4.9 during 1991-00 to 4.8 in 2001-08. The similar pattern was observed for Kharif and Prekharif season. Rabi season also show similar pattern except last decade.

The decadal annual APWS for Sylhet increased from 2.9 during $1956-60$ to 4.2 in 1961-70 and decreased from 4.2 during $1961-70$ to 3.1 in 2001-08. The similar pattern was found for Kharif and Prekharif season. The similar pattern is experienced for Kharif and Prekharif season. Rabi season also showed similar pattern with one exception for 1971-80.

The decadal annual APWS of Chittagong decreased from 5.1 during 1949-50 to 5.0 in 1951-60 and increased from 5.0 during 1951-60 to 6.3 in 1981-90 and decreased from 6.3 during $1981-90$ to 4.0 in 2001-08. The similar pattern was observed for Kharif with one exception for 1971-80 and Rabi season. During Prekharif season, APWS increased from 4.1 during 1949-50 to 5.8 in 1971-80 and decreased from 5.8 during $1971-80$ to 4.4 in 2001-08.

\subsection{Within-Year Variability}

The highest annual average APWS (5.5) was found in hilly and sea area of Chittagong and lowest (3.2) in Rajshahi (plain land). The highest APWS 6.7 was observed during Kharif, 5.4 during Prekharif and 4.1 during Rabi season in Chittagong while the lowest were noted 3.3 during Kharif season for Sylhet, 3.5 during Prekharif season and 2.5 during Rabi season for Rajshahi. The highest APWS were found in Prekharif season for all the stations except Rajshahi and Chittagong but lowest in Rabi season for all stations except Sylhet. The APWS were found same for the Kharif and Prekharif season of Rajshahi and Chittagong. The CVs were found highest in Prekharif season for Dhaka, Khulna and Chittagong, in Rabi season for Barisal and Sylhet and in Kharif season for Rajshahi. The CVs were found lowest in Rabi season for Dhaka, Khulna, Rajshahi and Chittagong but for Barisal and Sylhet, the lowest CVs were observed in Prekharif season.

\subsection{Between -Year Variability}

The rates obtained from LT for annual and seasonal APWS for six divisional stations are presented in Table 3. The growth rates for annual and seasonal APWS were found negative with nonstationary but normal residual for all regions except Barisal and the Prekharif season for Khulna. The rates for annual and seasonal APWS of Barisal were experienced positive with normal and nonstationary residual. 
Table 1. Decadal Averages for Annual and Seasonal APWS

\begin{tabular}{|c|c|c|c|c|c|c|c|c|c|c|c|c|c|c|c|c|c|c|c|c|c|c|c|c|c|c|c|c|c|}
\hline & \multicolumn{4}{|c|}{ Dhaka } & & \multicolumn{4}{|c|}{ Khulna } & & \multicolumn{4}{|c|}{ Rajshahi } & \multicolumn{5}{|c|}{ Barisal } & \multicolumn{5}{|c|}{ Sylhet } & & \multicolumn{4}{|c|}{ Chittagong } \\
\hline Period & $\mathbf{A}$ & $\mathbf{K}$ & $\mathbf{P k}$ & $\mathbf{R}$ & Period & $\mathbf{A}$ & $\mathbf{K}$ & $\mathbf{P k}$ & $\mathbf{R}$ & Period & $\mathbf{A}$ & $\mathbf{K}$ & $\mathbf{P k}$ & $\mathbf{R}$ & Period & $\mathbf{A}$ & $\mathbf{K}$ & $\mathbf{P k}$ & $\mathbf{R}$ & Period & $\mathbf{A}$ & $\mathbf{K}$ & $\mathbf{P k}$ & $\mathbf{R}$ & Period & $\mathbf{A}$ & $\mathbf{K}$ & $\mathbf{P k}$ & $\mathbf{R}$ \\
\hline- & & & & & $1948-50$ & 3.1 & 2.9 & 4.0 & 3.1 & - & & & & & $1949-50$ & 3.6 & 3.5 & 5.1 & 2.8 & - & & & & & $1949-50$ & 5.1 & 6.3 & 4.1 & 4.2 \\
\hline 1953-60 & 4.7 & 4.9 & 6.1 & 3.3 & $1951-60$ & 3.0 & 3.2 & 3.4 & 3.0 & - & & & & & $1951-60$ & 2.7 & 2.8 & 3.2 & 2.1 & $1956-60$ & 2.9 & 2.9 & 2.7 & 3.0 & $1951-60$ & 5.0 & 5.8 & 5.5 & 3.7 \\
\hline 1961-70 & 4.5 & 4.9 & 5.6 & 3.3 & $1961-70$ & 4.4 & 4.5 & 5.0 & 4.4 & 1964-70 & 2.8 & 2.9 & 3.0 & 2.4 & $1961-70$ & 3.7 & 3.9 & 4.4 & 3.0 & $1961-70$ & 4.2 & 4.1 & 4.6 & 3.9 & $1961-70$ & 5.7 & 7.3 & 5.6 & 3.7 \\
\hline $1971-80$ & 4.1 & 4.3 & 5.0 & 3.2 & $1971-80$ & 3.2 & 3.4 & 3.9 & 3.2 & $1971-80$ & 3.3 & 3.5 & 3.9 & 2.7 & $1971-80$ & 4.7 & 4.7 & 5.1 & 4.3 & $1971-80$ & 3.9 & 3.7 & 4.2 & 4.0 & $1971-80$ & 5.9 & 7.1 & 5.8 & 4.3 \\
\hline 1981-90 & 4.0 & 4.2 & 5.0 & 3.0 & $1981-90$ & 4.0 & 4.3 & 5.0 & 4.0 & $1981-90$ & 3.9 & 4.5 & 4.2 & 3.0 & $1981-90$ & 3.8 & \begin{tabular}{|l|}
3.9 \\
\end{tabular} & 4.4 & 3.3 & $1981-90$ & 3.4 & 3.3 & 3.9 & 3.3 & $1981-90$ & 6.3 & 7.9 & 5.6 & 5.0 \\
\hline 1991-00 & 2.9 & 3.0 & 3.4 & 2.4 & 1991-00 & 3.4 & 3.3 & 4.2 & 3.4 & 1991-00 & 2.8 & 3.1 & 3.2 & 2.2 & 1991-00 & 4.9 & 5.1 & 5.4 & 4.3 & 1991-00 & 3.1 & 2.8 & 3.6 & 2.9 & 1991-00 & 5.8 & 7.2 & 5.5 & 4.3 \\
\hline 2001-08 & 3.7 & 3.7 & 4.2 & 3.2 & 2001-08 & 2.6 & 2.8 & 3.0 & 2.6 & $2001-08$ & 2.7 & 2.9 & 2.8 & 2.3 & $2001-08$ & 4.8 & 4.8 & 5.7 & 4.0 & 2001-08 & 3.1 & 2.9 & 3.8 & 2.9 & $2001-08$ & 4.0 & 4.3 & 4.4 & 3.2 \\
\hline
\end{tabular}

Table 2. Within-Year Variability for Annual and Seasonal APWS

\begin{tabular}{|c|c|c|c|c|c|c|c|c|c|c|c|c|c|c|c|c|c|c|c|c|c|c|c|c|}
\hline & \multicolumn{4}{|c|}{ Dhaka } & \multicolumn{4}{|c|}{ Khulna } & \multicolumn{4}{|c|}{ Rajshahi } & \multicolumn{4}{|c|}{ Barisal } & \multicolumn{4}{|c|}{ Sylhet } & \multicolumn{4}{|c|}{ Chittagong } \\
\hline & $\mathbf{A}$ & $\mathbf{K}$ & PK & $\mathbf{R}$ & $\mathbf{A}$ & $\mathbf{K}$ & PK & $\mathbf{R}$ & $\mathbf{A}$ & $\mathbf{K}$ & PK & $\mathbf{R}$ & $\mathbf{A}$ & $\mathbf{K}$ & PK & $\mathbf{R}$ & $\mathbf{A}$ & $\mathbf{K}$ & PK & $\mathbf{R}$ & $\mathbf{A}$ & $\mathbf{K}$ & PK & $\mathbf{R}$ \\
\hline Max & 5.3 & 6.3 & 7.8 & 3.9 & 5.7 & 6.3 & 8.5 & 5.3 & 5.0 & 6.2 & 6.2 & 3.8 & 6.0 & 6.8 & 7.5 & 5.7 & 5.1 & 4.8 & 6.0 & 6.6 & 7.4 & 9.0 & 9.1 & 6.3 \\
\hline Ave & 4.0 & 4.2 & 4.9 & 3.1 & 3.4 & 3.6 & 4.1 & 2.7 & 3.2 & 3.5 & 3.5 & 2.5 & 4.1 & 4.2 & 4.7 & 3.5 & 3.5 & 3.3 & 3.9 & 3.4 & 5.5 & 6.7 & 5.4 & 4.1 \\
\hline Min & 2.1 & 2.2 & 2.3 & 1.7 & 2.0 & 1.9 & 1.7 & 1.5 & 2.1 & 2.0 & 2.2 & 1.8 & 1.4 & 1.2 & 1.7 & 1.2 & 1.8 & 1.7 & 1.8 & 1.8 & 2.5 & 2.4 & 2.2 & 1.7 \\
\hline $\mathbf{C V}$ & 19.3 & 22.1 & 24.2 & 17.2 & 24.9 & 28.0 & 31.1 & 25.8 & 22.2 & 26.8 & 26.3 & 17.3 & 26.0 & 28.0 & 27.1 & 29.2 & 19.4 & 23.7 & 21.8 & 23.9 & 18.7 & 23.0 & 33.8 & 22.1 \\
\hline
\end{tabular}


Table 3. Rates of LT for Annual and Seasonal APWS and the Residual's Stationarity and Normlity

\begin{tabular}{|l|r|r|r|r|}
\hline Stations & Annual & Kharif & Prekharif & \multicolumn{1}{|c|}{ Rabi } \\
\hline \multirow{2}{*}{ Dhaka } & $-0.0321(\mathrm{t}=-6.83$, & $-0.0382(\mathrm{t}=-$ & $-0.0490(\mathrm{t}=-6.73, \mathrm{~N}$, & $-0.0118(\mathrm{t}=-2.89, \mathrm{~N}$, \\
& $\mathrm{N}, \mathrm{NS})$ & $6.64, \mathrm{~N}, \mathrm{NS})$ & $\mathrm{NS})$ & $\mathrm{NS})$ \\
\hline \multirow{2}{*}{ Rajshahi } & $-0.0080(\mathrm{t}=-1.14$, & $-0.0086(\mathrm{t}=-$ & $-0.0050(\mathrm{t}=-$ & $-0.0095(\mathrm{t}=-2.33, \mathrm{~N}$, \\
& $\mathrm{Ap} . \mathrm{N}, \mathrm{NS})$ & $0.59, \mathrm{Ap} . \mathrm{N}, \mathrm{NS})$ & $1.05, \mathrm{Ap} . \mathrm{N}, \mathrm{NS})$ & $\mathrm{NS})$ \\
\hline \multirow{2}{*}{ Khulna } & $-0.0091(\mathrm{t}=-1.30, \mathrm{~N}$, & $-0.0063(\mathrm{t}=-1.19, \mathrm{~N}$, & $-0.0110(\mathrm{t}=-0.54, \mathrm{~N}$, & $-0.0112(\mathrm{t}=-1.91, \mathrm{~N}$, \\
& $\mathrm{NS})$ & $\mathrm{NS})$ & $\mathrm{NS})$ \\
\hline \multirow{2}{*}{ Barisal } & $+0.0381(\mathrm{t}=5.80, \mathrm{~N}$, & $+0.0381(\mathrm{t}=4.92, \mathrm{~N}$, & $+0.0395(\mathrm{t}=4.83, \mathrm{~N}$, & $\mathrm{NS})$ \\
& $\mathrm{NS})$ & $\mathrm{NS})$ & $+0.0371(\mathrm{t}=$ \\
\hline \multirow{2}{*}{ Sylhet } & $-0.0148(\mathrm{t}=-2.56, \mathrm{~N}$, & $-0.0188(\mathrm{t}=-2.82, \mathrm{~N}$, & $-0.0035(\mathrm{t}=-0.45, \mathrm{~N}$, & $-0.0183(\mathrm{t}=-2.66, \mathrm{~Np}$, \\
& $\mathrm{S})$ & $\mathrm{S})$ & $\mathrm{S})$ & $\mathrm{N}, \mathrm{S})$ \\
\hline Chittago & $-0.0067(\mathrm{t}=-$ & $-0.0132(\mathrm{t}=-1.15, \mathrm{~N}$, & $-0.0079(=\mathrm{t}-0.59, \mathrm{~N}$, & $+0.0023(\mathrm{t}=0.34, \mathrm{~N}$, \\
ng & $0.87, \mathrm{~N}, \mathrm{NS})$ & $\mathrm{NS})$ & $\mathrm{S})$ & $\mathrm{NS})$ \\
\hline
\end{tabular}

*Significant at 5\% level, S = Stationary, NS = Nonstationary, $\mathrm{N}=$ Normal Ap.N = Approximately normal, NN=Nonnormal

The rates obtained from $\mathrm{LT}$ for $\mathrm{CV}$ of annual and seasonal APWS for the six divisional stations are presented in Table 4 . The significant positive growth rate for CV of annual APWS was found for Khulna $\left(0.155^{*}\right)$ and the less positive rate for Rajshahi (0.011) with nonstationary residual while for other regions it was negative. During Kharif season, the less positive rates were acknowledged for Dhaka and Rajshahi and significant positive rate was noted for Khulna $(0.182 *)$. The fairly high negative rates were observed for Barisal and Sylhet while Chittagong ranked the lowest negative rate. During Prekharif season, the positive rate was documented for Khulna and negative for the rest five stations. For Rabi season, the positive rates were established for Dhaka and Khulna and the negative rates for rest of the four stations.

Table 4. Rates of LT for CVs of Annual and Seasonal APWS and The Residual's Stationarity and Normlity

\begin{tabular}{|c|c|c|c|c|}
\hline Station & Annual & Kharif & Prekharif & Rabi \\
\hline Dhaka & $\begin{array}{l}-0.139 *(\mathrm{t}=-2.24, \text { Ap. } \\
\mathrm{N}, \mathrm{S})\end{array}$ & $\begin{array}{l}+0.011(\mathrm{t}=0.12, \mathrm{NN}, \\
\mathrm{S})\end{array}$ & $\begin{array}{l}-0.285(\mathrm{t}=-3.77, \mathrm{~N}, \\
\mathrm{NS})\end{array}$ & $+0.147(\mathrm{t}=1.78, \mathrm{NN}, \mathrm{S})$ \\
\hline Rajshahi & $\begin{array}{l}+0.011(\mathrm{t}=0.11, \text { Ap.N, } \\
\text { NS })\end{array}$ & $\begin{array}{l}+0.052(\mathrm{t}=0.41, \text { Ap.N, } \\
\mathrm{S})\end{array}$ & $\begin{array}{l}-0.182(\mathrm{t}=-1.06, \mathrm{NN}, \\
\mathrm{S})\end{array}$ & $\begin{array}{l}-0.027(\mathrm{t}=-0.32, \mathrm{Ap}, \mathrm{N}, \\
\mathrm{S})\end{array}$ \\
\hline Khulna & $+0.155^{*}(\mathrm{t}=2.08, \mathrm{~N}, \mathrm{~S})$ & $\begin{array}{l}+0.182^{*}(\mathrm{t}=2.28 \\
\text { Ap.N, S })\end{array}$ & $\begin{array}{l}+0.073(\mathrm{t}=0.73, \mathrm{NN} \\
\mathrm{NS})\end{array}$ & $\begin{array}{l}-0.002(\mathrm{t}=- \\
0.03, \mathrm{Ap} . \mathrm{N}, \mathrm{S})\end{array}$ \\
\hline Barisal & $\begin{array}{l}-0.293(\mathrm{t}=-3.10, \mathrm{NN}, \\
\mathrm{S})\end{array}$ & $\begin{array}{l}-0.291(\mathrm{t}=-2.64, \mathrm{NN}, \\
\mathrm{S})\end{array}$ & $\begin{array}{l}-0.215^{*}(\mathrm{t}=- \\
3.56, \mathrm{Ap} . \mathrm{N}, \mathrm{S})\end{array}$ & $+0.053(t=0.60, N N, S)$ \\
\hline Sylhet & $\begin{array}{l}-0.176(\mathrm{t}=-1.74, \mathrm{NN}, \\
\mathrm{S})\end{array}$ & $\begin{array}{l}0.149(\mathrm{t}=-1.76 \\
\text { Ap.N, S) }\end{array}$ & $\begin{array}{l}-0.043(t=-0.43, A p \\
N, S)\end{array}$ & $-0.265^{*}(\mathrm{t}=-2.75, \mathrm{~N}, \mathrm{~S})$ \\
\hline Chittagong & $-0.122(\mathrm{t}=-1.51, \mathrm{~N}, \mathrm{~S})$ & \begin{tabular}{|l|}
$-0.006(=\mathrm{t}-$ \\
0.05$, Ap.N, S $)$
\end{tabular} & $-0.344(\mathrm{t}=-1.12, \mathrm{~N}, \mathrm{~S})$ & $-0.109(\mathrm{t}=-1.22, \mathrm{~N}, \mathrm{~S})$ \\
\hline
\end{tabular}

\subsection{Modelling and Forecasting}

The ARIMA models were fitted for replacing the detected outliers in some cases which are reported in Table 5. The data 9.6 for October 2008 was detected as outlier for Dhaka and that was forecasted from the fitted ARIMA models for 1953-2007 (square root transformed data) where the training set was taken for
1953-1998 and the validation set was chosen for 1999-2007. Finally, the outlier was replaced by 3.02.

The data 0.1 for May 1983, 1.5 for June 1983, 9.9 for July 1983 and 8.1 for June 1984 were detected as outliers for Rajshahi. The data for 1983-1984 were forecasted from the fitted ARIMA model for 19641982 where the training set was taken for 1964-1980 
and the validation set is assumed for 1981-1982. Finally, the outliers were replaced by 4.90 for May 1983, 4.49 for June 1983, 4.57 for June 1983 and 4.60 for July 1983.

The data 11.1 for January 1975, 6.3 for March 1975 and 8 for November 1975 were detected as outlier for Sylhet. The data for 1975 were forecasted from the fitted ARIMA model for 1956-1974 where the training set was taken from 1956-1972 and the validation set was chosen from 1973-1974. The data were replaced by 3.46 for January 1975, 3.87 for March 1975 and 3.10 for November 1975.

The data 12.9 for October 1960, 11.3 for October 1996 and 8.9 for April 2004 were detected as outlier for Barisal. The data for 1960 were forecasted from the fitted ARIMA models for 1949-1959 where 19491957 was taken as training set and 1958 - 1959 was taken as the validation set and the data for October 1960 is replaced by 2.64. Secondly, the data for October 1996 was forecasted from the fitted ARIMA models for 1949-1995 ( $\log$ transformed data) where the training set was taken from 1949-1993 and the validation set was taken from 1994-1995 and the outlier was replaced with the forecasted value 1.43. Lastly, the data for 2004 were forecasted from the fitted ARIMA model for 1949-2003 (square root transformed data) where the training set was taken from 1949-2001 and the validation set was chosen from 2002-2003 and the outlier for April 2004 was replaced with the forecasted value 5.75

Table 5. ARIMA Models for Replacing Outliers for Dhaka, Rajshahi and Sylhet and Barisal

\begin{tabular}{|c|c|c|c|c|c|c|}
\hline Variable & Model & Equation of Model & $\begin{array}{c}\text { MRMS } \\
\text { FE }\end{array}$ & SS & DF & MS \\
\hline Dhaka & $\begin{array}{c}\text { SQRT } \\
\text { ARIMA } \\
(100)(111)_{12}\end{array}$ & $\begin{array}{r}(1-0.3258 \mathrm{~B})\left(1-0.0606 \mathrm{~B}^{12}\right) \nabla_{12} \mathrm{y}_{\mathrm{t}}=-0.020250+(1- \\
\left.0.9306 \mathrm{~B}^{12}\right) \varepsilon_{\mathrm{t}} \\
\text { se of coeff. }(0.0378)(0.0433)(0.003144)(0.0166)\end{array}$ & 1.323 & 569.44 & 644 & 0.884 \\
\hline Rajshahi & $\begin{array}{c}\text { ARIMA } \\
(101)(011)_{12}\end{array}$ & $\begin{array}{c}(1-0.7777 \mathrm{~B}) \nabla_{12} \mathrm{y}_{\mathrm{t}}=0.018641+(1-0.2994 \mathrm{~B})\left(1-0.8668 \mathrm{~B}^{12}\right) \\
\varepsilon_{\mathrm{t}} \\
\text { se of coeff. }(0.0683)(0.005636)(0.1049)(0.0454)\end{array}$ & 0.799 & 101.38 & 212 & 0.478 \\
\hline Sylhet & $\begin{array}{c}\text { ARIMA } \\
(111)(111)_{12}\end{array}$ & $\begin{array}{c}(1-0.5953 \mathrm{~B})\left(1+0.1758 \mathrm{~B}^{12}\right) \nabla \nabla_{12} \mathrm{y}_{\mathrm{t}}=-0.0009770+(1- \\
0.9565 \mathrm{~B})\left(1-0.9170 \mathrm{~B}^{12}\right) \varepsilon_{\mathrm{t}} \\
\text { se of coeff. }(0.0611)(0.0749)(0.0007863)(0.0209) \\
(0.0434)\end{array}$ & 0.753 & 156.77 & 210 & 0.747 \\
\hline Barisal & $\begin{array}{c}\text { ARIMA } \\
(111)(011)_{12}\end{array}$ & $\begin{array}{c}(1+0.0244 \mathrm{~B}) \nabla \nabla_{12} \mathrm{y}_{\mathrm{t}}=0.002783+(1-0.4756 \mathrm{~B})(1- \\
\left.0.8448 \mathrm{~B}^{12}\right) \varepsilon_{\mathrm{t}} \\
\text { se of coeff. }(0.1885)(0.009529)(0.1623)(0.0719)\end{array}$ & 0.931 & 80.85 & 115 & 0.703 \\
\hline Barisal & $\begin{array}{l}\text { Ln ARIMA } \\
(111)(011)_{12}\end{array}$ & $\begin{array}{c}(1-0.9348 \mathrm{~B}) \nabla \nabla_{12} \mathrm{y}_{\mathrm{t}}=0.0007267+(1-0.5631 \mathrm{~B})(1- \\
\left.0.9659 \mathrm{~B}^{12}\right) \varepsilon_{\mathrm{t}} \\
\text { se of coeff. }(0.0193)(0.0002370)(0.0450)(0.0166)\end{array}$ & 0.687 & 30.36 & 548 & 0.055 \\
\hline Barisal & $\begin{array}{c}\text { SQRT T } \\
\text { ARIMA } \\
(101)(011)_{12}\end{array}$ & $\begin{array}{c}(1-0.9459 \mathrm{~B}) \nabla_{12} \mathrm{y}_{\mathrm{t}}=0.0005866+(1-0.6395 \mathrm{~B})(1- \\
\left.0.9574 \mathrm{~B}^{12}\right) \varepsilon_{\mathrm{t}} \\
\text { se of coeff. }(0.0169)(0.0001764)(0.0396)(0.0157)\end{array}$ & 0.248 & 30.55 & 644 & 0.047 \\
\hline
\end{tabular}

Finally, the ARIMA models were fitted for forecasting 2009-2012 where the training set is taken up to 1998 and validation set was taken from 1998-2008 which are shown in Table 6. The ACF displays for residual autocorrelations for the estimated models were fairly small relative to their standard errors for all the cases. The histograms of the residuals were symmetrical suggesting that the shocks might be normally or approximately normally distributed. The normal probability plots of the residuals did not deviate badly from straight lines (fairly close to a straight line), again suggesting that the shocks were normal. The point and interval forecasts for each APWS were presented in Table 7. Some TS plots for point and interval forecasts and residual plots are shown in Fig. 2. 

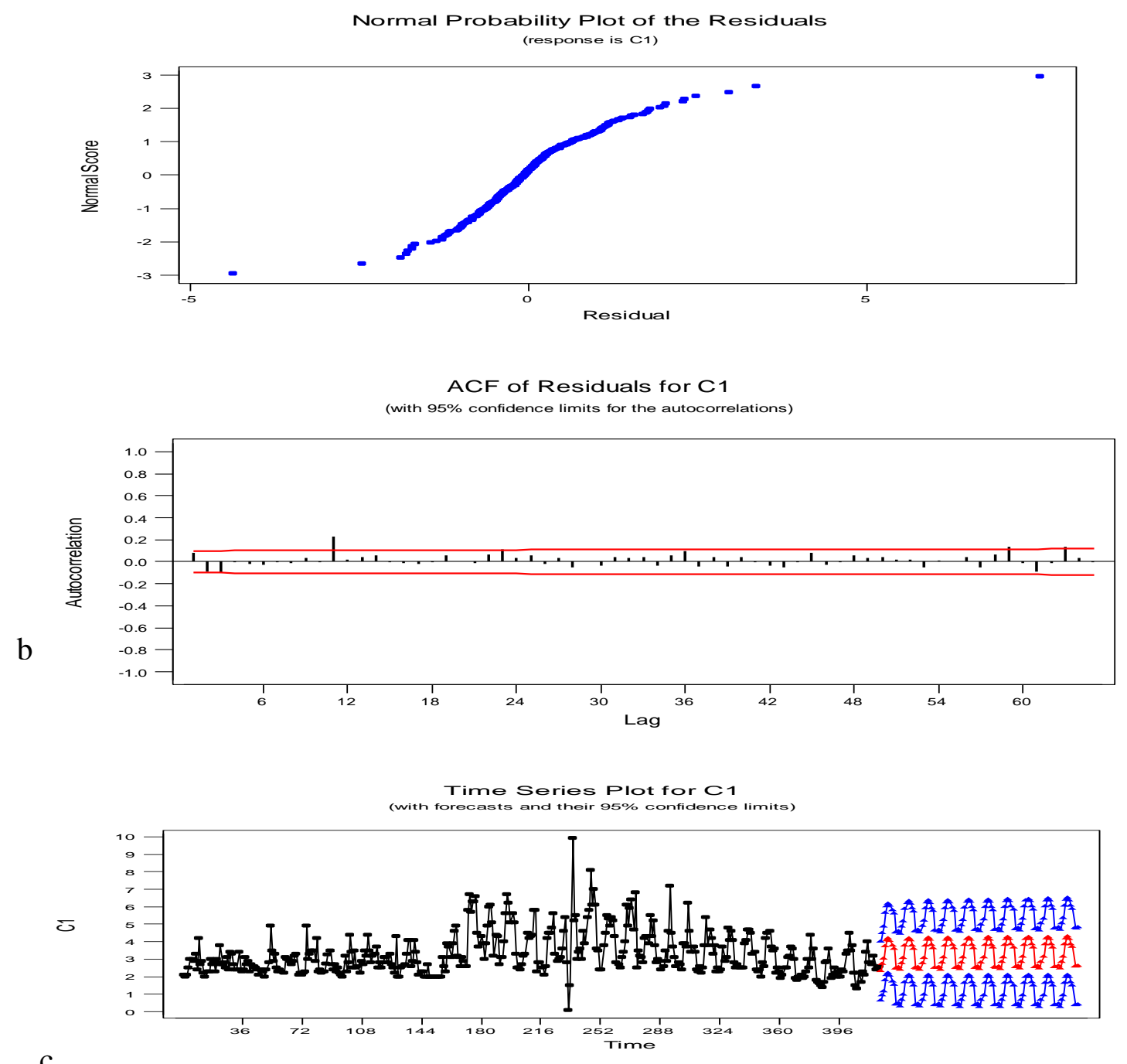

$\mathrm{c}$

Time Series Plot for $\mathrm{C4}$ (with forecasts and their $95 \%$ confidence limits)

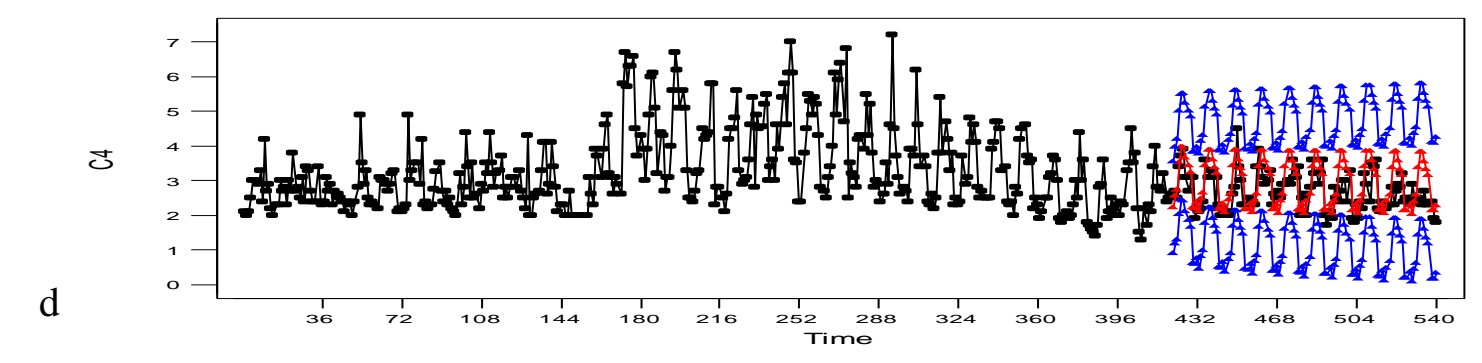

Fig. 2. (a) NP plot for residuals of Rajshahi (b) ACF display for residuals of Rajshahi (c) TS plot of Monthly APWS in Rajshahi and (d) Forecasted (Red line - Indication of point estimate and blue line - Indication of 95\% confidence interval) APWS for Rajshahi 
Table 6. Results of ARIMA Models for Monthly APWS for Six Stations

\begin{tabular}{|c|c|c|c|c|c|c|}
\hline Variable & Model & $\begin{array}{l}\text { Equation of Model } \\
\end{array}$ & MRMSFE & SS & DF & MS \\
\hline Dhaka & $\begin{array}{c}\text { ARIMA } \\
(100)(111)_{12}\end{array}$ & $\begin{array}{c}(1-0.3257 \mathrm{~B})\left(1-0.058 \mathrm{~B}^{12}\right) \nabla_{12} \mathrm{y}_{\mathrm{t}}=- \\
0.02011+\left(1-0.928 \mathrm{~B}^{12}\right) \varepsilon_{\mathrm{t}} \\
\text { se of coeff. }(0.0375)(0.0429)(0.003169)( \\
0.0167)\end{array}$ & 1.323 & 572.479 & 656 & 0.873 \\
\hline Rajshahi & $\begin{array}{c}\text { ARIMA } \\
(101)(111)_{12}\end{array}$ & $\begin{array}{c}\mathrm{y}_{\mathrm{t}}=-0.00037+(1-0.6844 \mathrm{~B})\left(1-0.8302 \mathrm{~B}^{12}\right) \\
\varepsilon_{\mathrm{t}} \\
\text { se of coeff. }(0.001732)(0.0324)(0.025)\end{array}$ & 0.535 & 245.122 & 254 & 0.468 \\
\hline Khulna & $\begin{array}{c}\text { SQRT T } \\
\text { ARIMA } \\
(111)(011) \\
12\end{array}$ & $\begin{array}{c}(1-0.2645 \mathrm{~B}) \nabla_{12} \mathrm{y}_{\mathrm{t}}=-0.00003 .76+(1- \\
0.8677 \mathrm{~B})\left(1-0.9655 \mathrm{~B}^{12}\right) \varepsilon_{\mathrm{t}} \\
\text { se of coeff. }(0.0455)(0.00006 .48)( \\
0.0232)(0.0113)\end{array}$ & 0.224 & $\begin{array}{c}42.937 \\
3\end{array}$ & 715 & 0.060 \\
\hline Barisal & $\begin{array}{c}\text { SQRT T } \\
\text { ARIMA } \\
(100)(111) \\
12\end{array}$ & $\begin{array}{c}(1-0.5975 \mathrm{~B})\left(1-0.0635 \mathrm{~B}^{12}\right) \nabla_{12} \mathrm{y}_{\mathrm{t}}= \\
0.003774+\left(1-0.9674 \mathrm{~B}^{12}\right) \varepsilon_{\mathrm{t}} \\
\text { se of coeff. }(0.0309)(0.0396)(0.000503) \\
(0.0148)\end{array}$ & 0.328 & $\begin{array}{c}37.538 \\
7\end{array}$ & 704 & 0.053 \\
\hline Sylhet & $\begin{array}{c}\text { ARIMA } \\
(101)(011) \\
12\end{array}$ & $\begin{array}{c}(1-0.8184 \mathrm{~B}) \nabla_{12} \mathrm{y}_{\mathrm{t}}=-0.00228+(1- \\
0.3265 \mathrm{~B})\left(1-0.9527 \mathrm{~B}^{12}\right) \varepsilon_{\mathrm{t}} \\
\text { se of coeff. }(0.0349)(0.001208)(0.0569) \\
(0.018)\end{array}$ & 0.633 & $\begin{array}{c}294.75 \\
0\end{array}$ & 620 & 0.475 \\
\hline $\begin{array}{c}\text { Chittago } \\
\text { ng }\end{array}$ & $\begin{array}{c}\text { 1949- } \\
\text { ARIMA } \\
(200)(111) \\
12\end{array}$ & $\begin{array}{c}(1-0.1614 \mathrm{~B})\left(1-0.0601 \mathrm{~B}^{2}\right)\left(1-0.1839 \mathrm{~B}^{12}\right) \nabla_{12} \\
\mathrm{y}_{\mathrm{t}}=-0.00518+\left(1-0.9596 \mathrm{~B}^{12}\right) \varepsilon_{\mathrm{t}} \\
\text { se of coeff. }(0.0377)(0.0378)(0.0394) \\
(0.005236)(0.0146)\end{array}$ & 3.204 & $\begin{array}{c}3517.5 \\
2\end{array}$ & 703 & 5.0 \\
\hline
\end{tabular}

*SQ RT T -Square root transformed, MRMSFE-Minimum root mean square forecasting error, SS=Sum square error, $\mathrm{DF}=$ Degrees of Freedom, MS-Mean square error, se of coeff.-Standard error of coefficient

Table 7. Point and Interval Forecasts of Monthly APWS

\begin{tabular}{|c|c|c|c|c|c|c|c|c|c|c|c|c|c|c|c|c|}
\hline \multirow[t]{2}{*}{ Period } & \multicolumn{2}{|c|}{ Dhaka for 2009} & \multicolumn{3}{|c|}{ Rajshahi for 2009} & \multicolumn{3}{|c|}{ Khulna for 2009} & \multicolumn{2}{|c|}{ Barisal for 2009} & \multicolumn{6}{|c|}{\begin{tabular}{|l|l} 
Sylhet for 2009 & $\begin{array}{l}\text { Chittagong for } \\
2009\end{array}$
\end{tabular}} \\
\hline & \begin{tabular}{|l|l|} 
PE & $\mathrm{IE}(\mathrm{L})$ \\
\end{tabular} & $\mathrm{IE} / \mathrm{I}$ & $\mathrm{PE}$ & $\mathrm{IF}(\mathrm{L})$ & $\mathrm{IE}(\mathrm{U})$ & $\mathrm{PE}$ & IF/I & & \begin{tabular}{|l|l|}
1.89 & 1.44 \\
\end{tabular} & 2.35 & \begin{tabular}{|l|l|}
$\mathrm{PE}$ \\
\end{tabular} & $\mathrm{IE}(\mathrm{L})$ & $\operatorname{IE}(\mathrm{U})$ & $\mathrm{PE}$ & $\mathrm{IE}(\mathrm{L})$ & $\mathrm{IE}(\mathrm{U})$ \\
\hline & \begin{tabular}{|l|l|}
2.88 & 1.05 \\
\end{tabular} & 4.71 & 1.88 & 0.54 & 3.22 & & & 1.82 & & 2.59 & 2.48 & 1.12 & 3.83 & 3.66 & -0.73 & 8.05 \\
\hline & \begin{tabular}{|l|l|}
2.88 & 0.96 \\
\end{tabular} & 4.81 & 1.95 & 0.54 & 3.36 & & 0.88 & 1.91 & \begin{tabular}{|l|l|}
2.20 & 1.65 \\
\end{tabular} & 2.76 & 3.00 & 1.49 & 4.50 & 4.44 & 0.00 & 8.88 \\
\hline March & \begin{tabular}{|l|l|}
3.69 & 1.76 \\
\end{tabular} & 5.63 & 2.08 & 0.61 & 3.55 & 1.59 & & 2.12 & \begin{tabular}{|l|l|}
2.40 & 1.84 \\
\end{tabular} & 2.96 & 3.53 & 1.93 & 5.13 & 4.83 & 38 & 29 \\
\hline April & \begin{tabular}{|l|l|}
3.94 & 2.01 \\
\end{tabular} & 5.88 & 2.59 & 1.06 & 4.12 & 1.70 & & 2.24 & \begin{tabular}{|l|l|}
2.43 & 1.86 \\
\end{tabular} & 2.99 & 3.44 & & 5.11 & 5.49 & 3 & 95 \\
\hline May & \begin{tabular}{|l|l|}
3.64 & 1.70 \\
\end{tabular} & 5.58 & 2.51 & 0.92 & 4.09 & 1.73 & 1.18 & 2.27 & \begin{tabular}{|l|l|}
2.34 & 1.78 \\
\end{tabular} & 2.91 & 3.28 & & 4.98 & 4.70 & .24 & 9.16 \\
\hline June & \begin{tabular}{|l|l|}
3.18 & 1.25 \\
\end{tabular} & 5.12 & 2.59 & 0.95 & 4.23 & 1.62 & 1.07 & 2.17 & \begin{tabular}{|l|l|}
2.28 & 1.71 \\
\end{tabular} & 2.84 & 2.89 & 1.16 & 4.62 & 4.47 & 0.01 & 8.93 \\
\hline July & \begin{tabular}{|l|l|}
3.20 & 1.26 \\
\end{tabular} & 5.14 & 2.70 & 1.01 & 4.40 & 1.56 & 1.00 & 2.12 & \begin{tabular}{|l|l|}
2.27 & 1.71 \\
\end{tabular} & 2.83 & 2.98 & 1.23 & 4.72 & 7.14 & 2.68 & 11.60 \\
\hline August & \begin{tabular}{|l|l|}
3.16 & 1.22 \\
\end{tabular} & 5.10 & 2.44 & 0.69 & 4.18 & 1.58 & 1.02 & 2.15 & \begin{tabular}{|l|l|l|}
2.23 & 1.66 \\
\end{tabular} & 2.79 & 2.87 & 1.12 & 4.63 & 6.57 & 2.11 & 11.02 \\
\hline Septe & \begin{tabular}{|l|l|l|l|} 
& 3.24 & 1.30 \\
\end{tabular} & 5.18 & 2.64 & 0.84 & 4.43 & 1.51 & 0.93 & 2.08 & \begin{tabular}{|l|l|l|}
2.22 & 1.66 \\
\end{tabular} & 2.79 & 2.66 & 0.89 & 4.42 & 5.64 & 1.18 & 10.10 \\
\hline October & \begin{tabular}{|l|l|}
2.95 & 1.01 \\
\end{tabular} & 4.88 & 1.88 & 0.04 & 3.73 & 1.39 & 0.81 & 1.97 & \begin{tabular}{|l|l|l|}
2.04 & 1.47 \\
\end{tabular} & 2.60 & 2.71 & 0.94 & 4.48 & 5.04 & 0.58 & 9.50 \\
\hline & \begin{tabular}{l|l|l|l|} 
& 2.51 & 0.57 \\
\end{tabular} & 4.44 & 1.65 & -0.25 & 3.54 & 1.22 & 0.64 & 1.81 & \begin{tabular}{|l|l|}
2.11 & 1.54 \\
\end{tabular} & 2.67 & 2.77 & 00 & 4.55 & 3.23 & -1.23 & 7.69 \\
\hline December & \begin{tabular}{|l|l|l|l|}
2.33 & 0.39 \\
\end{tabular} & 4.27 & 1.77 & -0.17 & 3.71 & 1.24 & 0.65 & 1.84 & \begin{tabular}{|l|l|l|}
1.89 & 1.44 \\
\end{tabular} & 2.35 & 2.77 & 0.99 & 4.54 & 3.17 & -1.29 & 7.63 \\
\hline
\end{tabular}

PE-Point estimate IE (L)-Interval estimate (lower limit) IE (U) - Interval estimate (upper limit) 
Table 7. continued

\begin{tabular}{|c|c|c|c|c|c|c|c|c|c|c|c|c|c|c|c|}
\hline & \multicolumn{2}{|c|}{ Dhaka for 2010} & \multicolumn{3}{|c|}{ Rajshahi for 2010} & \multicolumn{2}{|c|}{ Khulna for 2010} & \multicolumn{3}{|c|}{ Barisal for 2010} & \multicolumn{5}{|c|}{\begin{tabular}{|l||l} 
Sylhet for 2010 & Chittagong for 2010
\end{tabular}} \\
\hline & \begin{tabular}{l|l|}
$\mathrm{PE}$ & $\mathrm{IE}(\mathrm{L})$ \\
\end{tabular} & & $\mathrm{PE}$ & $\mathrm{IE}(\mathrm{L})$ & $\mathrm{IE}(\mathrm{U})$ & \begin{tabular}{|l|l|} 
PE & IE(L) \\
\end{tabular} & $\mathrm{IE}(\mathrm{U})$ & PE & $\mathrm{IE}(\mathrm{L})$ & IE(U) & PE $|\mathrm{IE}(\mathrm{L})|$ & $\mathrm{IE}(\mathrm{U})$ & & $\mathrm{IE}(\mathrm{L})$ & $\mathrm{IE}(\mathrm{U})$ \\
\hline & $2.49 \mathrm{C}$ & 4.45 & 1.78 & & 3.83 & & & & & & & & & & \\
\hline & & & & & & & & & & & & & & & \\
\hline & 62 & 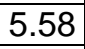 & & & & & & & & & 3.71 & & & & \\
\hline & & 89 & & & 4. & & & & & & & & & & \\
\hline & & & & & & & & & & & & & & & \\
\hline & & & & & & & 23 & & & & & 77 & & & \\
\hline & & & & & & & 17 & & & & & & & & \\
\hline & \begin{tabular}{|l|l|}
3.15 & 1.20 \\
\end{tabular} & & & -0 . & & & 20 & & & & & & & & \\
\hline & \begin{tabular}{|l|l|}
3.24 & 1.28 \\
\end{tabular} & 19 & 2.53 & & & & 13 & 5 & & & & & & & 0.57 \\
\hline & 2.910 & 86 & & & & & & & & & & & & & \\
\hline & & 43 & & & & & & & & & & & & & 7.97 \\
\hline & \begin{tabular}{|l|l|}
2.24 & 0.29 \\
\end{tabular} & 20 & .67 & & 4.29 & .220 .55 & 1.89 & & 5 & 2.71 & \begin{tabular}{|l|l|}
2.79 & 1.00 \\
\end{tabular} & & & .34 & 7.80 \\
\hline
\end{tabular}

Table 7. continued

\begin{tabular}{|c|c|c|c|c|c|c|c|c|c|c|c|c|c|c|}
\hline Period & Dhaka f & & & & & Khulnaf & & Barisal ff & & 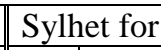 & 011 & \multicolumn{3}{|c|}{ Chittagong for 2011} \\
\hline & \begin{tabular}{l|l} 
PE & IE( \\
\end{tabular} & & PE & $\mathrm{IE}(\mathrm{L})$ & $\mathrm{IE}(\mathrm{U})$ & \begin{tabular}{l|l} 
PE & $\mathrm{IE}(\mathrm{L})$ \\
\end{tabular} & & \begin{tabular}{l|l} 
PE & IE $(\mathrm{L}$ \\
\end{tabular} & $\mathrm{IE}(\mathrm{U})$ & \begin{tabular}{l|l} 
PE & IE $(\mathrm{L}$ \\
\end{tabular} & $\mathrm{IE}(\mathrm{U})$ & $\mathrm{PE}$ & $\mathrm{IE}(\mathrm{L})$ & $\mathrm{IE}(\mathrm{U})$ \\
\hline ry & \begin{tabular}{|l|l|}
2.44 & 0.48 \\
\end{tabular} & 4.40 & 1.67 & & 4.40 & \begin{tabular}{l|l|}
1.32 & 0.65
\end{tabular} & 2.00 & & & \begin{tabular}{|l|l|}
2.77 & 0.98 \\
\end{tabular} & & & & 8.39 \\
\hline ebr & \begin{tabular}{|l|l|}
2.69 & 0.74 \\
\end{tabular} & & .74 & & .52 & & & & & \begin{tabular}{|l|l|}
3.23 & 1.44 \\
\end{tabular} & & & & 29 \\
\hline Marc & 3.5 & & & & & & 2.24 & \begin{tabular}{|l|l|}
2.32 & 1 \\
\end{tabular} & & $\overline{93}$ & & & & .49 \\
\hline pril & 3.901 & & & & 5.2 & $\begin{array}{l}1.650 .96 \\
\end{array}$ & 2.35 & \begin{tabular}{|l|l|}
2.48 & 1 \\
\end{tabular} & & \begin{tabular}{ll|l}
3.59 & 1
\end{tabular} & & & & 0.00 \\
\hline Иay & 3.59 & & 30 & & 5.25 & \begin{tabular}{l|l|}
1.68 & 0.98
\end{tabular} & 2.38 & 2.501 & $3 .(\mathrm{C}$ & 3.39 & & 4.70 & & 9.29 \\
\hline une & 3.11 & & 38 & & 5.38 & 1.57 & 2.28 & 2.40 & 2.97 & 2.98 & .77 & 4.48 & & 9.06 \\
\hline July & 3.13 & 08 & .49 & & 5.55 & 1.51 & 2.23 & \begin{tabular}{|l|l|l|}
2.32 & 1 \\
\end{tabular} & 2.89 & 3.05 & 4.84 & 7.77 & & 2.35 \\
\hline ugu & \begin{tabular}{|l|l|l|}
3.12 & 1 \\
\end{tabular} & 08 & 2.22 & & 5.33 & 1.54 & 2.26 & \begin{tabular}{|l|l|}
2.31 & 1 \\
\end{tabular} & 2.88 & \begin{tabular}{l|l|}
2.92 & 1.13
\end{tabular} & 4.71 & .11 & & 11.69 \\
\hline pte & \begin{tabular}{l|l|l|}
$\mathrm{r}$ & 3.21 & 1.25 \\
\end{tabular} & 1 & .43 & & 5.5 & 1.460 & 2.19 & \begin{tabular}{|l|l|}
2.26 & 1 \\
\end{tabular} & 2.83 & 69 & 4.48 & 07 & & 10.65 \\
\hline ctol & \begin{tabular}{|l|l|}
2.88 & 0.92 \\
\end{tabular} & 4.84 & .67 & & 4.88 & 1.340 & 2.08 & \begin{tabular}{|l|l}
2.25 & 1.
\end{tabular} & 2.81 & \begin{tabular}{l|l|}
.74 & 0.95
\end{tabular} & 4.53 & 5.17 & & 9.75 \\
\hline over & \begin{tabular}{|l|l|l|}
2.44 & 0.4 \\
\end{tabular} & 4.40 & 1.43 & & 4.69 & \begin{tabular}{|l|l|}
1.18 & 0.44 \\
\end{tabular} & 1.91 & \begin{tabular}{|l|l|}
2.07 & 1.50 \\
\end{tabular} & 2.63 & \begin{tabular}{l|l|}
2.79 & 1.00 \\
\end{tabular} & 4.58 & 3.42 & -1.16 & 8.01 \\
\hline ecemb & \begin{tabular}{l|l}
2.21 & 0.25 \\
\end{tabular} & 4.17 & .56 & -1.75 & 4.87 & \begin{tabular}{l|l}
1.200 .45 \\
\end{tabular} & 1.94 & \begin{tabular}{|l|l|}
2.15 & 1.59 \\
\end{tabular} & 2.72 & \begin{tabular}{l|l}
2.78 & 0.99
\end{tabular} & 4.57 & 3.24 & -1.35 & 7.82 \\
\hline
\end{tabular}

Table 7. continued

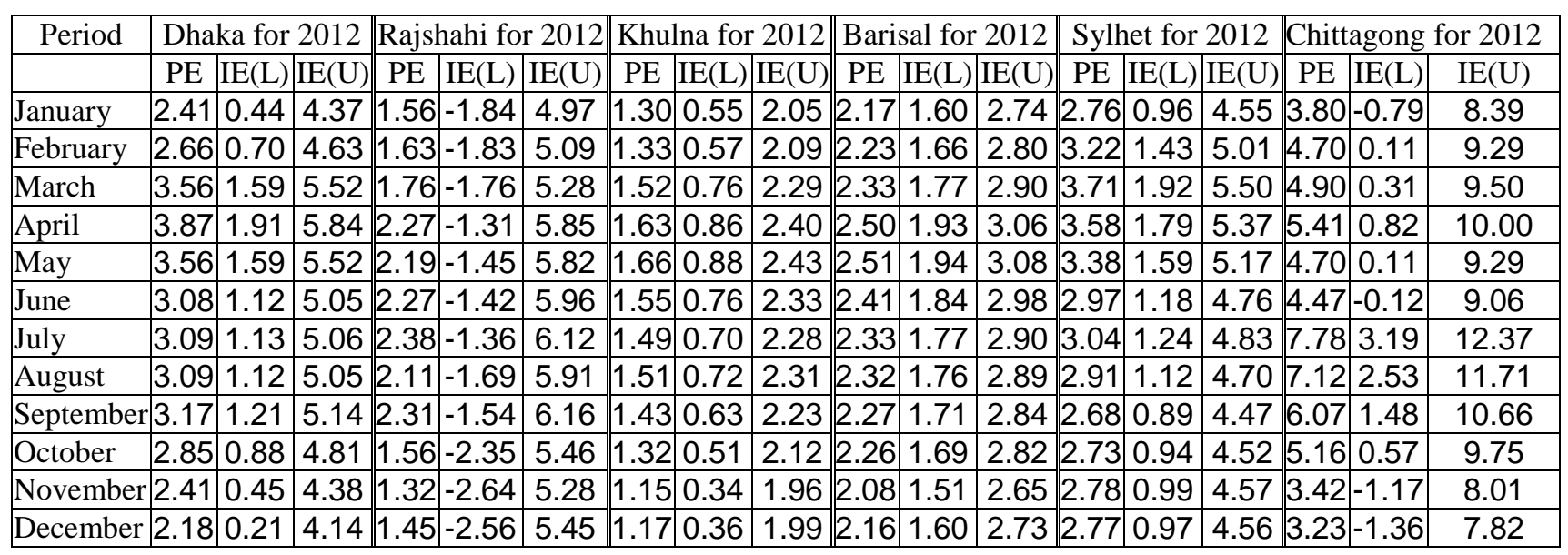




\section{Conclusions}

The growth rates for annual and seasonal APWS were observed to be negative with nonstationary but normal residual for all regions except Barisal and the Prekharif season for Khulna. The rates for Barisal were positive with the normal and nonstationary residual. The significant positive growth rate for $\mathrm{CV}$ of annual APWS was documented for Khulna $\left(0.155^{*}\right)$ and the less positive rate for Rajshahi (0.011) with nonstationary residual while for other regions it was negative. The aforesaid forecasted values for monthly APWS during 2009-2012 were obtained from the best fitted ARIMA (autoregressive integrated moving average) models and those models were selected on the basis of minimum root mean square forecasting error for last ten years of 120 observations amongst the set of models for a particular station. The selected models for Dhaka, Rajshahi, Khulna, Barisal, Sylhet, Chittagong were ARIMA(100)(111) 12, ARIMA(101)(111) ${ }_{12}$, SQRT T ARIMA(111)(011) 12, SQRT T ARIMA(100)(111) 12 , $\operatorname{ARIMA}(101)(011) \quad 12$ and $\operatorname{ARIMA(200)(111)~12,~}$ respectively
The findings pinpointed that the climate of this country was decreasing in terms of wind-speed and judicious planning is very much essential to suit with the changes for sustainable development of her agriculture.

\section{References}

Box, G. E. P and Jenkins, G. M. 1976. Time Series Analysis: Forecasting and Control, Prentince Hall, Inc.575p.

Lenka, D.1998. Climate Weather and Crops in India, Kalyani Publishers, 23 Daryagang, New Delhi110002, India, 114 p.

Pankraiz, A. 1991. "Forecasting with Dynamic Regression Models" John Wiley and Sons Inc, New York.

SMRC. 2000. "Recent Climatic Changes in Bangladesh" SMRC Report No. 4, South Asian Association for Regional Cooperation, Dhaka, Bangladesh. 